\title{
MANAGING A SUSTAINABLE SUPPLY CHAIN - STATISTICAL ANALYSIS OF NATURAL RESOURCES IN THE FURNITURE INDUSTRY
}

\author{
Anna WIŚNIEWSKA-SAŁEK \\ Czestochowa University of Technology
}

\begin{abstract}
:
Managing a sustainable supply chain is a concept related to many areas of the economy. Its efficient functioning depends on the implementation of SDG activities and the development of industry (first-fourth/fifth industrial revolution). Due to the likelihood of different priorities in the implementation of the sustainable development goals, it is important to build such relationships, e.g. in the supply chain, so that their implementation could take place under similar conditions. Digitization, or the circular economy concept (CE), create an opportunity for the SME sector to build relationships as part of industry networks, for instance, where the managed supply chain would have a common and realistic goal to achieve. This goal will be a priority in business models based on sustainable development. The article presents the results of research regarding the furniture industry in Poland (key industry, referred to as smart specialization). The results of the analysis show that the industry has a large production potential, and the natural resources used in it are constantly increasing. However, there are doubts raised by the lack of stability in the dynamics of the sold production in the industry. Ultimately, the business model of the industry supply chain should focus on the environmental aspect (sustainable management of the raw material supply chain) and on eco-friendly consumption (sustainable management of the product supply chain), so that it can be managed in a sustainable way.
\end{abstract}

Key words: sustainability, sustainable development, SSCM, circular economy concept, Industry 4.0

\section{INTRODUCTION}

Sustainable development is a kind of environmental "must have" in the current economic reality. Implementation of SDGs sets a trend for the development of enterprises to be "environmentally friendly", which has become a bargaining chip in the media competition of brands. Caring for natural resources along with continuous concern for their renewal and digitization of the industry have made companies able to outdo each other in the implementation of innovative technologies. Increasingly more enterprises operate online [1], which indirectly contributed to a different approach to quality [2,3] and to consumption, increasing its virtual dimension.

Activities carried out as part of sustainable development can be reduced to collaboration between the concept of Industry 4.0 and the concept of circular economy. The fourth industrial revolution is preceded by electricity or automation of the production line. What makes it different from the previous revolutions is that it applies to all aspects of life, which in turn is a common area with the SDGs (Sustainable Development Goals). The processing and commercialization of information in the human-machine and machine-machine relationship is the assumption of Industry 4.0 [4]. The concept of circular economy applies to both industrial ecology and environmental economics. It was introduced to achieve a balance between the three pillars of sustainable development. However, it has a limited scope and scale of activities. Nevertheless, the continuous development of technology and emerging new business models provide opportunities for organizations to increase sustainable results through CE principles. The global economy of today has the tools to manage it in an appropriate and sustainable manner. Taking into account that the vast majority of national economies is mainly composed of the SME sector, a global network of connections (e.g. clusters) should be used that will create equal growth opportunities for all enterprises that are part of a sustainably managed network (industry) supply chain.

\section{LITERATURE REVIEW}

Sustainability: the fundamental term of the $21^{\text {st }}$ century. Used by many organizations due to its essential role in the 
development of companies in the context of the profits achieved by them, preserving social and environmental values $[5,6]$. Maintaining sustainability applies to three main pillars: environment, economy and society. These attitudes are characterised by caring for the natural environment and maintaining the independence of society through continuous access to resources that enable them to meet their economic and social needs [7]. Due to such a wide area of activities, sustainability is a term described in many disciplines and in various fields:

- economic sustainability - production processes aimed at satisfying the current level of consumption without disturbing the course of meeting future needs: cost versus benefit ratio [8];

- lifestyle and energy consumption - lifestyle changes multiplied in general consumption standards [9]. For example, small groups (various types of movements or networks) in which participants conduct information meetings on environmental and social issues, which ultimately led to a significant reduction in resource consumption and household waste [10]. Research published by Biespot \& Noorman suggests that adjusting habits to expenses causes changes, for example, in low energy consumption among all income groups (such as transport or home insulation) [11];

- sustainable education - inclusion of all elements of education, i.e. teaching programs and techniques in the area of sustainability. Another example is deep learning support, which regards the use of highly effective educational practices, e.g. community-based sustainability projects $[12,13,14]$;

- sustainable professional - a response to sustainable education by creating a job in this area. It is so universal that technical or scientific education allows for further development in the field of engineering, urban planning, statistics, psychology, or environmental sciences and marketing. The need for such education/professions results from the presence of sustainability issues in every sector or industry in economies around the world [15];

- sustainable technology - technology management (MOT)[9] in order to define sustainable areas (technological innovation and new product development [16, $17,18])$ to maintain technological competitiveness on the market [19].

The measure of sustainability is the level of its development. Sustainable development is defined by the World Commission on Environment and Development as "the development that meets the needs of the present without compromising the ability of future generations to meet their own needs" [20]. Sustainable development is a rapidly developing area of research and its definition and interpretation are approached in different ways. The implementation of the idea of sustainable development, due to the increasing participation in economic activity, requires new methods allowing for the integration of various spheres [21]. Sustainable development based on three pillars is approached through two different points of view:
- weak sustainability - it consists of sacrificing one pillar at the expense of another one. Such limitations cause weak sustainability to evolve into strong sustainability, and vice versa;

- strong sustainability - the environment is the most important pillar, but it covers the way to social and sustainable development. This situation blocks the possibility of economic development.

Despite the contradictions in setting their priorities and political consequences, the integration of the sustainable development pillars is perceived in both perspectives as a coherent system [22]. The actions that can be implemented for sustainable development are defined in the Agenda for Sustainable Development. It is a global call to action for sustainable development and covers areas such as poverty eradication, reducing inequalities and combating climate change [23]. The 17 goals defined in the SDGs are "integrated and indivisible" [24]. The integration of the goals of the three sustainable development pillars of an organization in the field of systemic coordination of key inter-organizational business processes aims to improve the long-term economic results of enterprises, including the supply chain. This concept defines sustainable supply chain management - SSCM $[25,26]$. It is an extension of the concept of the supply chain (which, measured not only by the economy but also influenced by the environment and the social system, becomes fully sustainable SSC [27]), which includes Reverse Logistics and Green Supply Chain Management [28]. The current economy identifies SSCM as the key to corporate responsibility and a way to maintain brand integrity along with managing operating costs [29]. In practice, achieving an SSCM is not that simple, and decision makers in companies have to make choices between sustainability priorities, which are often competitive. It should be taken into account that a significant percentage of suppliers belong to the SME sector, therefore it is important to make the development of SSCM dependent on a better understanding of corporate social responsibility and sustainable development, especially in these organizations [30, 31].

\section{METHODOLOGY OF RESEARCH}

The research process was aimed at checking, what type of wood is most often obtained in the form of large timber. Then, the sales volume of the selected type of wood was analysed, and then companies processing wood into furniture were characterized. The whole constitutes a process of managing the natural resource in the form of wood in the chain of its supply to furniture companies.

The quantitative research used tools for statistical analysis. The dynamics study was used to determine the variability of the number of furniture industry entities registered at the National Business Registry (REGON) along with their dynamics of industrial production sold and sales of a specific group of wood. Correlation and regression study to verify the type of the most frequently obtained wood grade (large timber) as well as the relationship between newly registered and deregistered furniture companies. An integrated programming environment for the 
$R$ language (RStudio) and an advanced business analysis tool (Power BI Desktop) were used to perform the calculations and present the data.

The data for analysis was obtained from the Central Statistical Office in Poland, using the Local Data Bank tool, and from the State Forests, using the Forest and Wood website. Due to the different process of data publication, the time range covered the years: 2009-2019 (REGON); 2002-2019 (timber acquisition); 2011-2020 (sales of wood). The subject of the study covers the territory of Poland broken down into Provinces in the case of the analysis of furniture companies.

\section{RESULTS OF RESEARCH}

\section{Wood acquisition}

The analysis of the wood data was primarily focused on examining what type of wood has the greatest impact on the overall timber acquisition (large timber). Study results (Figure 1) defining the relationship coefficient are specified by the following variables $\left[\mathrm{m}^{3}\right]$ :

$Y$ - Acquisition of wood (large timber);

$\mathrm{X} 1$ - softwood large timber for general purposes;

X2 - softwood large timber for special purposes;

X3 - softwood thickness medium-sized long wood;

$X 4$ - softwood medium timber for industrial processing;

X5 - softwood large timber for firing purposes;

X6 - hardwood large timber for general purposes;

X7 - hardwood large timber for special purposes;

$\mathrm{X} 8$ - hardwood medium timber, long wood;

X9-hardwood medium timber for industrial processing; $\mathrm{X} 10$ - hardwood large timber for firing purposes;

X11 - small-sized wood;

$\mathrm{X} 12$ - fatwood.

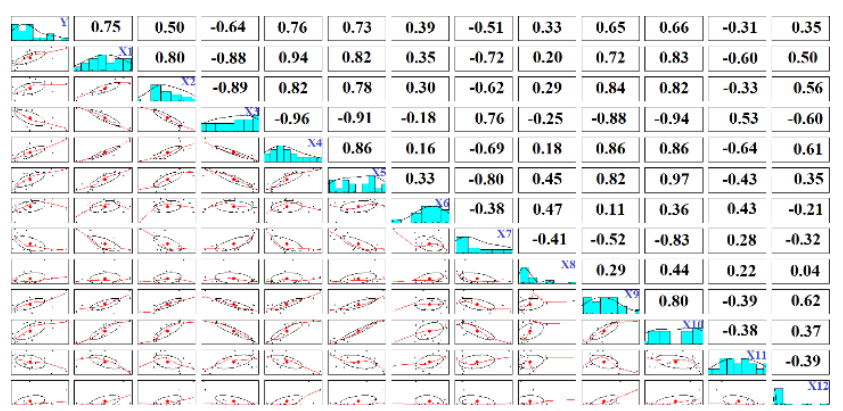

Fig. 1 Research on the relationship of acquired wood (large timber)

Source: own study based on data [32].

The correlation study shows the highest correlation between the $X 4$ variable (negative correlation) with the $X 3$ variable and with the $X 1$ variable (positive correlation). This means that when the $X 4$ variable grows, the $X 3$ variable decreases and the $X 1$ variable grows. A detailed analysis of the model of the dependent variable $(Y)$ and the explanatory variables (X1-X12) is presented in the table below (Table 1).
Table 1

Statistical analysis of acquired wood (large timber) model in

Poland

\begin{tabular}{ccccc}
\hline Coefficients & Estimate & Std. Error & t value & $\operatorname{Pr}(>|\mathbf{t}| \mathbf{)}$ \\
\hline (Intercept) & $-4.725 \mathrm{e}+06$ & $1.569 \mathrm{e}+06$ & -3.011 & $0.0297^{*}$ \\
X1 & $-8.450 \mathrm{e}-02$ & $1.227 \mathrm{e}-01$ & -0.689 & 0.5217 \\
X2 & $4.693 \mathrm{e}+00$ & $7.027 \mathrm{e}+00$ & 0.668 & 0.5338 \\
X3 & $3.265 \mathrm{e}+00$ & $1.291 \mathrm{e}+00$ & 2.530 & 0.0525 \\
X4 & $3.215 \mathrm{e}-01$ & $1.067 \mathrm{e}-01$ & 3.013 & $0.0297^{*}$ \\
X5 & $1.052 \mathrm{e}+00$ & $4.107 \mathrm{e}-01$ & 2.561 & 0.0506. \\
X6 & $1.218 \mathrm{e}-02$ & $6.616 \mathrm{e}-01$ & 0.018 & 0.9860 \\
X7 & $1.866 \mathrm{e}+00$ & $1.660 \mathrm{e}+00$ & 1.124 & 0.3120 \\
X8 & $-3.096 \mathrm{e}+01$ & $1.110 \mathrm{e}+02$ & -0.279 & 0.7914 \\
X9 & $-4.705 \mathrm{e}-01$ & $3.086 \mathrm{e}-01$ & -1.525 & 0.1879 \\
X10 & $1.983 \mathrm{e}-01$ & $4.392 \mathrm{e}-01$ & 0.452 & 0.6705 \\
X11 & $4.884 \mathrm{e}-01$ & $4.118 \mathrm{e}-01$ & 1.186 & 0.2889 \\
X12 & $2.064 \mathrm{e}+01$ & $1.657 \mathrm{e}+01$ & 1.246 & 0.2681 \\
\hline
\end{tabular}

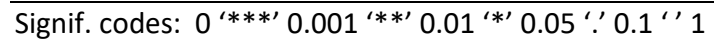

Residual standard error: 86890 on 5 degrees of freedom Multiple R-squared: 0.9517, Adjusted R-squared: 0.8359 F-statistic: 8.215 on 12 and 5 DF, p-value: 0.01513

Source: own study based on data [32].

The linear model (based on the above data) has the following form:

$$
\begin{gathered}
y=-4724919,344-0.084 x_{1}+4.693 x_{2}+3.265 x_{3}+ \\
0.322 x_{4}+1.052 x_{5}+0.012 x_{6}+1.866 x_{7}-30.963 x_{8}- \\
0.471 x_{9}+0.198 x_{10}+0.488 x_{11}+20.642 x_{12}
\end{gathered}
$$

The analysis of the coefficients shows that the variables in the model are interdependent and adjusted well. The value of the standard error and the coefficient of variation prove the homogeneity of the studied population. Statistical significance was confirmed for the $X 4$ variable (its importance in the model is within the $1-5 \%$ error range) and for the $X 3$ and $X 5$ variables (5-10\% estimate error range). In order to clarify what type of wood (large timber) has the greatest impact on obtaining natural resources from forests, another model has been formulated. It contains only those variables that were confirmed to be statistically significant in the general model. The results of the relationships are presented in the chart below (Figure 2).

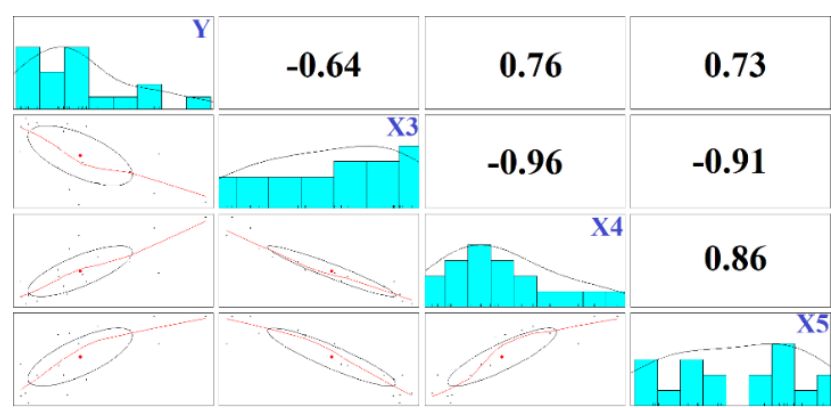

Fig. 2 Study of the relationships of the acquired wood (large timber) for selected variables

Source: own study based on data [32].

A detailed analysis of the model explained by the $X 3, X 4$ and $\mathrm{X} 5$ variables is presented in the table below (Table 2 ). 
Table 2

Statistical analysis of the acquired wood (large timber) model for selected variables in Poland

\begin{tabular}{ccccc}
\hline Coefficients: & Estimate & Std. Error & t value & $\operatorname{Pr}(>|t|)$ \\
\hline (Intercept) & $-2.645 \mathrm{e}+06$ & $7.846 \mathrm{e}+05$ & -3.371 & $0.004570^{* *}$ \\
X3 & $2.093 \mathrm{e}+00$ & $5.056 \mathrm{e}-01$ & 4.141 & $0.001000^{* * *}$ \\
X4 & $1.627 \mathrm{e}-01$ & $3.470 \mathrm{e}-02^{* * *}$ & 4.688 & $0.000349^{* * *}$ \\
X5 & $7.252 \mathrm{e}-01$ & $2.121 \mathrm{e}-01$ & 3.419 & $0.004154^{* *}$ \\
\hline
\end{tabular}

Signif. codes: 0 ‘***' $0.001^{\prime * * \prime} 0.01^{\prime * \prime} 0.05$ '. $0.1^{\prime \prime} 1$

Residual standard error: 99740 on 14 degrees of freedom

Multiple R-squared: 0.8219 , Adjusted R-squared: 0.7838

F-statistic: 21.54 on 3 and 14 DF, p-value: $1.64 \mathrm{e}-05$

Source: own study based on data [32].

The linear model (based on the above data) has the following form:

$$
y=-264493+2.093 x_{3}+0.163 x_{4}+0.725 x_{5}
$$

The analysis of the coefficients confirms good matching of the model with empirical data and the relationship of the variables. The $\mathrm{X} 4$ variable has the greatest probability of influence (99.97\%) on the explained variable. The X3 and X5 variables have an estimation error of $0.1 \%$ and $0.4 \%$, respectively. The analysis of the impact of the explanatory variables median (X3-X5) on the average change of the dependent variable $(\mathrm{Y})$ is shown in Figure 3.

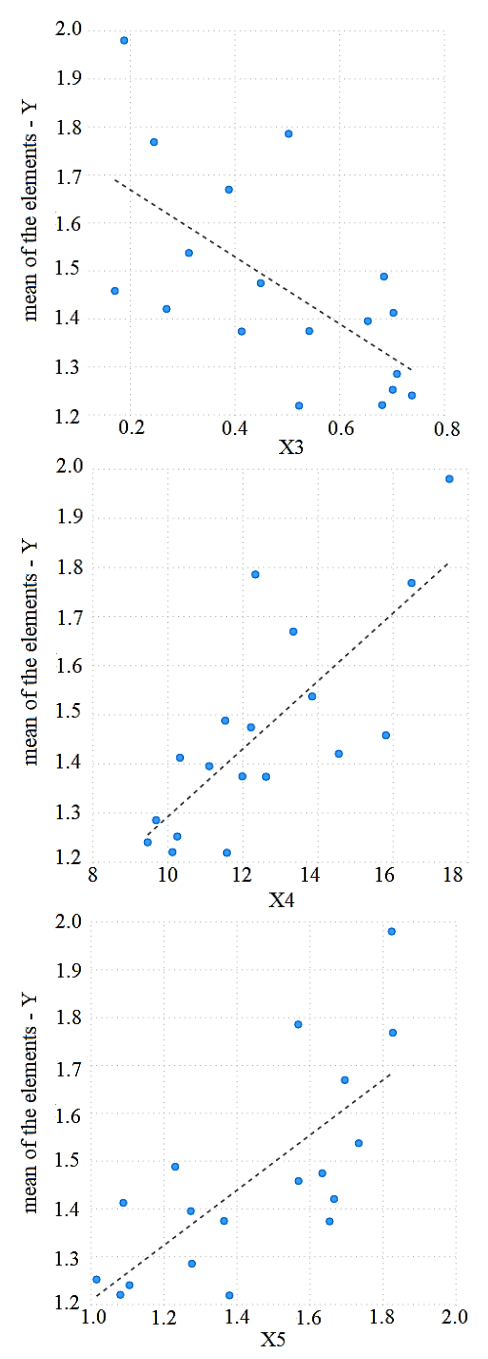

Fig. 3 Key elements affecting the size of acquired wood (hard timber) for selected variables [ $\mathrm{m} / \mathrm{n}^{3}$ ]

Source: own study based on data [32].
Based on the data, the greatest compliance with the trend line is noticeable for the $\mathrm{X} 4$ variable. This variable, as in the case of the $X 5$ variable, shows an increase in its median value along with an increase in the mean value of the $Y$ variable. In the case of the $X 3$ variable, the trend line suggests that its increase in its median causes a decrease in the average of the $Y$ variable. However, due to its large dispersion, it cannot be taken as an unequivocal statement.

\section{Wood sales}

The next stage of the analysis regards the characteristics of the variability of wood sales in forest districts in Poland (Figure 4). The selected assortment group was examined, which was indicated by the model (as a group of explanatory variables with the greatest impact on the explained variable). The analysis regarded the sale of wood obtained from conifers (types: SO-pine; SWspruce) broken down into medium-sized stacked wood (assortment group: S2A-industrial and general purpose; S2B-for mechanical processing).

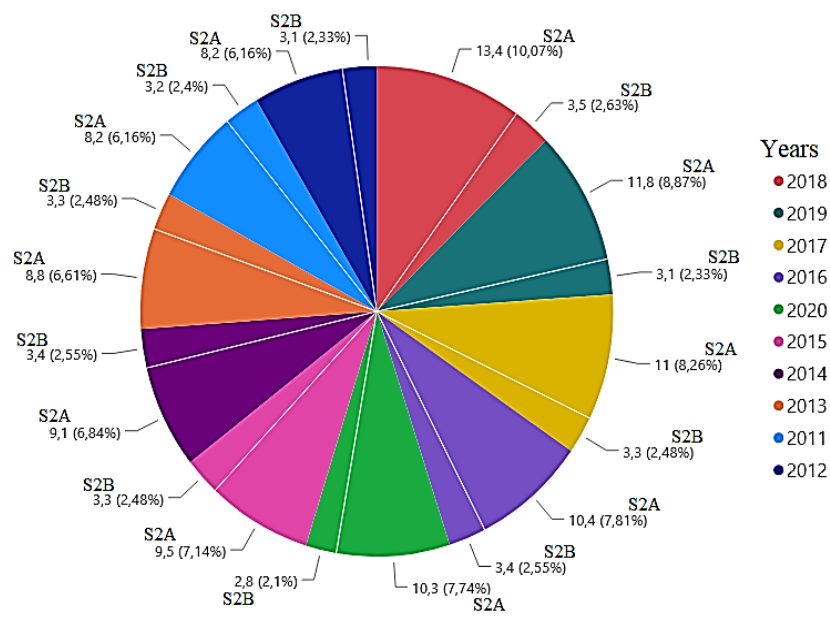

Fig. 4 Sales of coniferous wood in Poland in 2011-2020 [million $\mathrm{m}^{3}$ ]

Source: own study based on data [33].

The share of individual assortment groups is relatively evenly distributed. In the following years, approx. 27$37 \%$ of S2B wood compared to S2A wood was sold. A detailed analysis of the sale (median) of a particular type of wood (coniferous) in relation to its quantity and price is presented in Figure 5.

Data analysis shows an increasing amount of wood sold for SO type and a fixed amount for SW type in individual assortment groups. Both types of coniferous trees show noticeable fluctuations in prices, but a similarly spreading trend within one assortment group for its different types. 


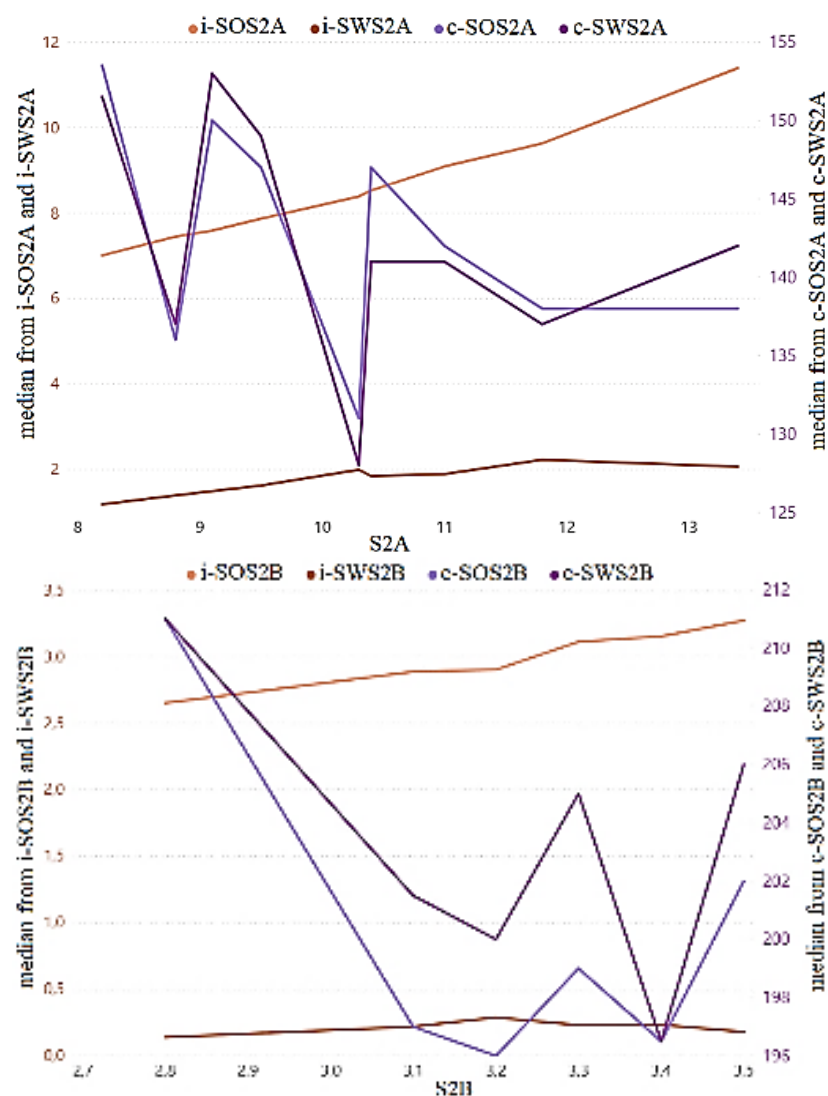

Fig. 5 Quantity (i) [million m3] and price (c) [PLN/ $\left.\mathrm{m}^{3}\right]$ of selling coniferous wood assortment groups in Poland in 2011-2020 Source: own study based on data [33].

\section{Furniture companies - analysis}

The characteristics of the furniture industry in Poland relates to the analysis of the number of registered companies in REGON, both newly registered and deregistered companies. The identification of enterprises was based on the Polish Classification of Activities (PKD 2007) according to its scheme: Section C - Industrial manufacturing; Division 31 - Manufacture of furniture. The input data was used to calculate the dynamics of entities in the furniture industry in Poland in the context of examining their impact on the dynamics of industrial production sold in fixed prices. Study results (Figure 6) defining quantitative [thou. pcs] and/or percentage [\%] relations are determined by the following variables:

YR - annual number of companies in the REGON database;

YRd - dynamics of companies in the REGON database;

YW - annual number of deregistered companies;

YWd - dynamics of deregistered companies;

$\mathrm{YZ}$ - annual number of newly registered companies;

YZd - dynamics of newly registered companies;

PSd - dynamics of sold production of industry.
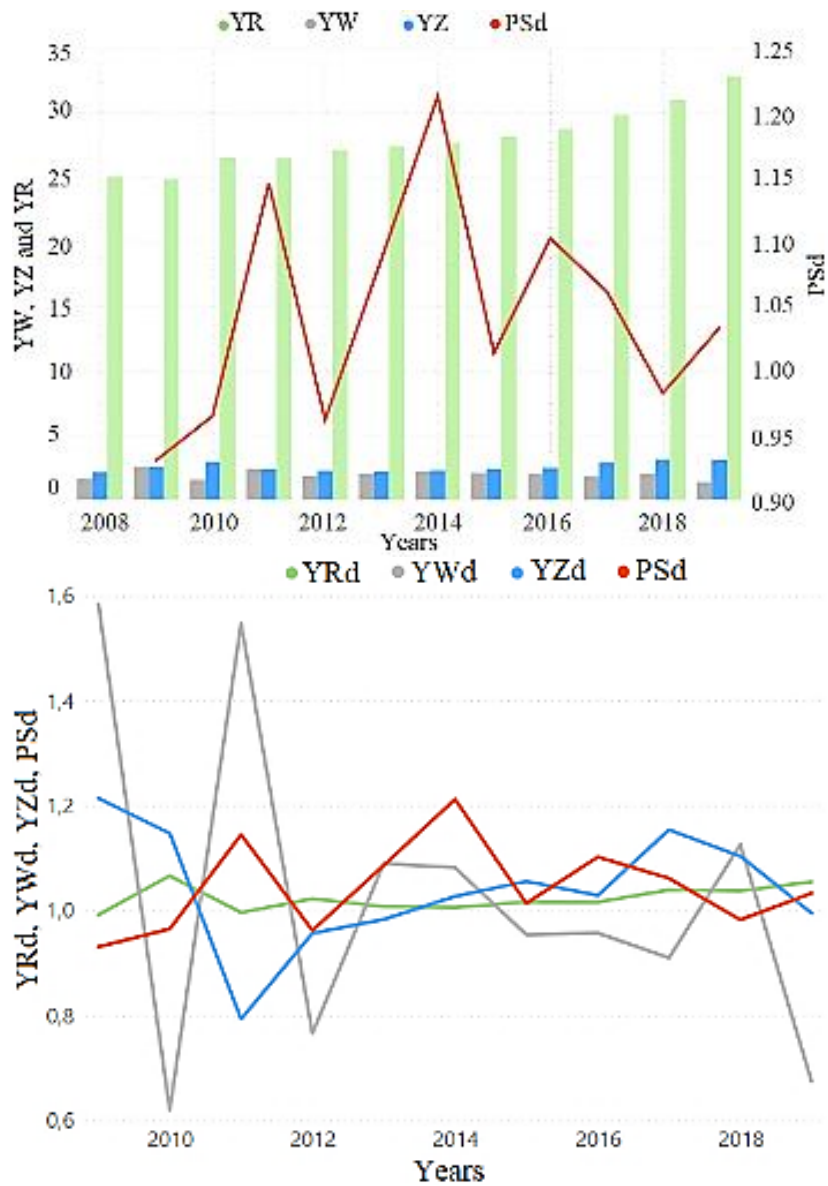

Fig. 6 Reports of companies from the furniture industry and their dynamics of production sold in Poland in 2009-2019 Source: own study based on data [32].

The above data shows the greatest stability for companies registered in the REGON database. The other variables showed the opposite situation, where the highest variability was recorded for companies that withdrew from the database. Fluctuations in the dynamics of sold production do not translate into the annual growth of companies in the industry. Confirmation of these relationships is the low correlation between its variables (Figure7).

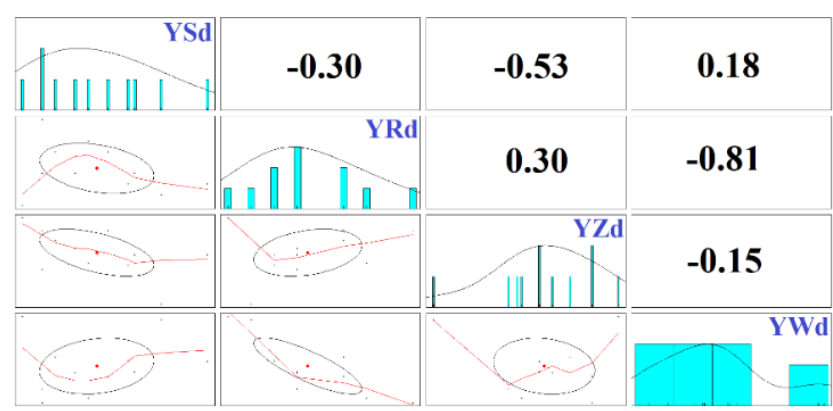

Fig. 7 Study of the relations of sold production of industry at fixed prices for selected variables

Source: own study based on data [32]. 
The lack of proportionality in dynamics is visible in the correlation of variables. Values close to zero indicate no relationship between deregistered and newly registered companies. The relationship between deregistered enterprises and the general register is visible, as can also be seen in Figure 6 (increase in YR causes decrease in YW: significant negative correlation). Additionally, the average correlation confirms the relationship between the dynamics of production sold and the number of newly registered enterprises (the reduced volatility of the PSd dynamics is caused by the increasing dynamics of YZd). A detailed analysis of the model explaining the dynamics of industrial output sold with the use of the explained variables is presented by the linear model taking into account the data from Table 3, in the following form:

$$
y_{P S d}=2.228-0.775 x_{Y R d}-0.36 x_{Y Z d}-0.016 x_{Y W d}
$$

Table 3

Statistical analysis of the model of the dynamics of industrial production sold [at fixed prices] for selected variables in Poland

\begin{tabular}{|c|c|c|c|c|}
\hline Coefficients & Estimate & Std. Error & t value & $\operatorname{Pr}(>|t|)$ \\
\hline (Intercept) & 2.22820 & 2.21558 & 1.006 & 0.348 \\
\hline YRd & -0.77475 & -2.09751 & -0.369 & 0.723 \\
\hline YZd & -0.36026 & -0.25077 & -1.437 & 0.194 \\
\hline YWd & -0.01626 & 0.15152 & -0.107 & 0.918 \\
\hline
\end{tabular}

Residual standard error: 0.08603 on 7 degrees of freedom Multiple R-squared: 0.3075, Adjusted R-squared: 0.01073 F-statistic: 1.036 on 3 and 7 DF, p-value: 0.4334

Source: own study based on data [32].

The analysis of the model confirms the previous conclusions. Therefore, it can be stated that the dynamics of industrial production sold is not related to the dynamics of companies in a given industry. A low value of the correlation coefficient indicates a bad match of the data to the model. High estimation errors (72\%, 20\% and 92\%) indicate that the variables do not statistically significantly affect the explained variable.

\section{DISCUSSION}

Research carried out in Poland shows that conifers have the greatest impact on the volume of wood obtained from forests in the form large timber. The most common timber is medium-sized for industrial processing, long timber and firewood. Statistical analysis showed the highest share in obtaining wood (large timber) for the purpose of medium-sized wood for industrial processing. Its share in the acquisition of large timber increased by 6.3 [thousand $\mathrm{m}^{3}$ ] in 2019, when compared to 2002, while the total large timber increased by 0.2 [thousand $\mathrm{m}^{3}$ ]. The importance of this type of wood is visible in the share of conifers in the sale of wood in forest districts in Poland. The most commonly sold coniferous wood is pine in the assortment group of medium-sized stacked woo for industrial and general purpose. When calculating the values that the forest inspectorate earned on the sale of this assortment group, a decrease by 31.13 [million PLN] can be noticed, comparing 2020 to 2011, with a lower price and an increased quantity analogously by $30\left[\mathrm{PLN} / \mathrm{m}^{3}\right]$ and 2.1 [million $\mathrm{m}^{3}$ ]. When analysing the supply chain of natural resources, the side of the seller and buyer of the raw material should be taken into account. Therefore, a group of companies from the furniture industry was subject to the study. Due to the large share of the furniture industry in the export of furniture in the world, in Poland each year there is an increase in enterprises producing furniture by about 2-4\%. Comparing 2009 to 2019, there was an increase by less than 8 [thousand] companies listed in the National Official Register of Entities of the National Economy. Changes in the demand for natural raw materials should be influenced by the number of newly registered and deregistered enterprises from division $D$ of section C31 (PKD2007). The study showed that the change in one group was not affected by the change in the other group. Taking into account the production potential of the industry, the number of deregistered enterprises should be taken into account, the growth of which will reduce the population of the REGON register. When attempting to estimate the production sold against the production capacity, the analysis of the dependencies showed a very small impact of enterprises (their number) on the value of production sold. Therefore, it can be concluded that despite the increase in sales of the raw material at a reduced price and the growing number of furniture producing companies, the dynamics of production sold is subject to high volatility.

\section{CONCLUSIONS}

Designing a supply chain that will take into account the aspects of sustainable development requires the use of dedicated tools (including those relating to the assessment of product life in the context of sustainable development). Supply chain management requires a decisionmaking process that extends its traditional format to include the principles of sustainable development. Introducing environmental protection issues into it allows you to create pro-environmental attitudes in a potentially satisfied consumer. The operation of such a new chain allows the conservation of earth's resources, reducing the negative impact on the natural environment.

The conducted research showed an increase in the production potential of companies operating in the furniture industry in Poland. Thus, it has been shown that the sale of natural resources such as wood, has been growing. Despite the positive dynamics, the analysis of the sold production showed high variability. Taking into account the sale of furniture and its share in the national economy, as well as the leading position in the export ranking, it can be concluded that the dynamic volatility of sales is determined not by the continuity of production, but the temporary lack of orders for these products. Poland has adequate wood resources as well as a modern machine park. These factors strengthen the high position of Polish furniture among competitors in the industry on global markets. Furniture personalization, changing trends resulting 
from the changing tastes of subsequent generations, automation of production or digitization of the design process make it difficult to manage supply chain while maintaining balance in the management of natural resources. Statistical analysis showed that more and more timber is obtained from forests. The demand for it is constantly growing, due to the increasing number of companies in the furniture industry. Thus, the dynamics of sold production is not stable. The development of the industry depends on natural raw materials. Special attention should be paid to the environmental aspect in terms of the decision-making process when building business models that makes it possible to manage the supply chain of natural raw materials in a sustainable manner. The sale of wood should be closely correlated with the filling of the resulting gaps (increased sale and timber acquisition), i.e. afforestation of forest land. On the other hand, the furniture supply chain should be managed to ensure strengthening of the rational and pro-ecological consumerism for furniture (variable sold production). Both models make it possible to manage the supply chain of the furniture industry in a sustainable manner, thus supplementing the raw materials used and stabilizing production sales.

\section{REFERENCES}

[1] N. Baryshnikova, O. Kiriliuk, and D. Klimecka-Tatar, "Enterprises' strategies transformation in the real sector of the economy in the context of the COVID-19 pandemic," Production Engineering Archives, vol. 27, no. 1, pp. 8-15, 2021, doi: 10.30657/pea.2021.27.2.

[2] D. Siwiec, and A. Pacana, "Method of improve the level of product quality", Production Engineering Archives, vol. 27, no. 1, pp. 1-7, 2021, DOI: 10.30657/pea.2021.27.1.

[3] M. Ingaldi, and R. Ulewicz, "Evaluation of quality of the ecommerce service", International Journal of Ambient Computing and Intelligence, vol. 9, Issue: 2, 2018, pp. 55-66, doi:10.4018/IJACI.2018040105.

[4] B. Ślusarczyk, "Industry 4.0 - Are we ready?," Polish J. Manag. Stud., vol. 17, no. 1, pp. 232-248, 2018, doi: 10.17512/pjms.2018.17.1.19.

[5] P. Ghosh, A. Jha, and R. Sharma, "Managing carbon footprint for a sustainable supply chain: a systematic literature review," Mod. Supply Chain Res. Appl., vol. 2, no. 3, pp. 123-141, 2020, doi: 10.1108/mscra-06-2020-0016.

[6] A. Kolk, and J. Pinkse, "A perspective on multinational enterprises and climate change: learning from 'an inconvenient truth'?", Journal of International Business Studies, vol. 39, no. 8, pp. 1359-1378, 2008, doi: 10.1057/jibs.2008.61.

[7] S. Lazar, D. Klimecka-Tatar and M. Obrecht, "Sustainability Orientation and Focus in Logistics and Supply Chains", Sustainability, vol. 13(6), 3280, 2021, doi: 10.3390/su13063280.

[8] R.L.H. Chiu, "Sustainability", International Encyclopedia of Housing and Home, vol.7, pp. 91-96, 2012, doi: http://dx.doi.org/10.1016/B978-0-08-047163-1.00688-3.

[9] C.A. Bollino, and P. Polinori, "Chapter 6 - Sustainability: Will There Be the Will and the Means?", Energy, Sustainability and the Environment Technology, Incentives, Behavior, pp. 137-164, 2011, https://doi.org/10.1016/B978-012-385136-9.10006-3.
[10] T. Jackson, and L. Michaelis, "Policies for Sustainable Consumption A Report to the Sustainable Development Commission Policies for Sustainable Consumption", Sustainable Development Commission, 2003.

[11] W. Biesiot and K. J. Noorman, "Energy requirements of household consumption: A case study of The Netherlands," Ecol. Econ., vol. 28, no. 3, pp. 367-383, 1999, doi: 10.1016/S0921-8009(98)00113-X.

[12] W. O'Brien and J. Sarkis, " 3 - U.S. and international community-based sustainability projects for deep learning", Sustainability in Higher Education, pp. 51-65, 2015, https://doi.org/10.1016/B978-0-08-100367$1.00003-2$

[13] L.T. Hansen, S. Dann, and J.M. Kerr, "A Critical Learning Cycle Model for Sustainability Education: Two Case Studies of Water Conservation Programs in Jordan", Journal of Sustainability Education, vol. 3, 2012.

[14] W. O'Brien, and J. Sarkis, "The potential of communitybased sustainability projects for deep learning initiatives", Journal of Cleaner Production, vol. 62, pp. 48-61, 2014, https://doi.org/10.1016/j.jclepro.2013.07.001.

[15] T. Abdallah, "Chapter 10 - Continuous Sustainability in Mass Transit", Sustainable Mass Transit, Challenges and Opportunities in Urban Public Transportation, pp. 141-157, 2017, https://doi.org/10.1016/B978-0-12-8112991.00010-1.

[16] D. Klimecka-Tatar, and M. Ingaldi, "Assessment of the technological position of a selected enterprise in the metallurgical industry", Materials Research Proceedings, vol. 17, pp. 72-78, 2020, doi: https://doi.org/10.21741 /9781644901038-11.

[17] L. Oubahman, and S. Duleba, S., "Review of PROMETHEE method in transportation", Production Engineering Archives, vol. 27, no. 1, pp. 69-74, 2021, doi: 10.30657/pea.2021.27.9.

[18] R. Ulewicz, F. Nový, and J. Selejdak, "Fatigue strength of ductile iron in ultra-high cycle regime", Advanced Materials Research, vol. 874, pp. 43-48, 2014, doi: 10.4028/www.scientific.net/AMR.874.43.

[19] S. Jun, "Bayesian count data modeling for finding technological sustainability," Sustain., vol. 10, no. 9, 2018, doi: $10.3390 /$ su10093220

[20] "WCED Our Common Future", World Commission on Environment and Development, Oxford University Press, 1987,

[21] P. Brzustewicz, „Zarządzanie łańcuchem dostaw a cykl życia produktu - Perspektywa rozwoju zrównoważonego", Marketing i Rynek, vol.12, pp.8-13.

[22] V. Mohamad Taghvaee et al., "Sustainable development goals: transportation, health and public policy," Rev. Econ. Polit. Sci., 2021, doi: 10.1108/reps-12-2019-0168.

[23] United Nations, "Transforming our world: the 2030 agenda for sustainable development", 2015, https://sdgs.un.org/2030agenda

[24] J. Castor, K. Bacha, and F. Fuso Nerini, "SDGs in action: A novel framework for assessing energy projects against the sustainable development goals," Energy Res. Soc. Sci., vol. 68, no. May, pp. 101556, 2020, doi: 10.1016/j.erss.2020.101556.

[25] L. Bunclark and L. Barcellos-Paula, "Sustainability reporting for sustainable supply chain management in Peru," Sustain. Prod. Consum., vol. 27, pp. 1458-1472, 2021, doi: 10.1016/j.spc.2021.03.013.

[26] S. Kot, "Sustainable supply chain management in small and medium enterprises," Sustain., vol. 10, no. 4, pp. 1-19, 2018, doi: $10.3390 /$ su10041143. 
[27] J. Yang and J. Černevičiūtè, "Cultural and creative industries (CCl) and sustainable development: China's cultural industries clusters," Entrep. Sustain. Issues, vol. 5, no. 2, pp. 231-242, 2017, doi: 10.9770/jesi.2017.5.2(6).

[28] D. Wittstruck, and F. Teuteberg, "Understanding the success factors of sustainable supply chain management: empirical evidence from the electrics and electronics industry", Corp. Soc. Responsib. Environ. Manag, vol. 19, no.3, pp. 141-158, 2012, doi: 10.1002/ csr.261.

[29] J.K. Roehrich, J. Grosvold, and S.U. Hoejmose, "Reputational risks and sustainable supply chain management: decision making under bounded rationality", Int. J. Oper. Prod. Manag, vol. 34, no. 5, pp. 695-719, 2014, doi: 10.1108/IJOPM-10-2012-0449.

\section{Anna Wiśniewska-Sałek}

ORCID ID: 0000-0003-4537-3225

Czestochowa University of Technology

Faculty of Management

Department of Production Engineering and Safety ul. Armii Krajowej 19 B, 42-200 Częstochowa, Poland

e-mail: anna.wisniewska-salek@wz.pcz.pl
[30] M. Niciejewska and O. Kiriliuk, "Occupational health and safety management in "small size" enterprises, with particular emphasis on hazards identification," Production Engineering Archives, vol. 26, no. 4, pp. 195-201, 2020, doi: 10.30657/pea.2020.26.34.

[31] S. Kot, A. UI Haque, A. Baloch, "Supply Chain Management in SMEs: Global Perspective", Montenegrin Journal of Economics, vol.16, no. 1 , pp. 87-104, 2020, doi: 10.14254/1800-5845/2020.16-1.6.

[32] "Statistics Poland", https://bdl.stat.gov.pl/BDL/dane/podgrup/temat

[33] "Forest and Wood Portal of the State Forests", http://drewno.zilp.lasy.gov.pl/drewno/ 